\title{
Resenha: \\ A Ifigênia em Áulis de Eurípides por Christopher Collard e James Morwood
}

Félix Jácome Neto ${ }^{1}$

O recorte temporal da intriga de Ifigénia em Áulis (daqui em diante, IA) de Eurípides situa-se imediatamente antes da guerra entre gregos e troianos, quando os primeiros estão retidos em Áulis à espera de ventos propícios para continuarem a navegação até Troia. A peça abre com um inquieto Agamêmnon que acaba de se arrepender de ter enviado uma carta a Argos solicitando que Clitemnestra trouxesse Ifigênia para se casar com Aquiles em Áulis. Este casamento revelar-se-ia falso, pois o intuito inicial do Atrida era trazer a filha ao acampamento grego para sacrificá-la, única maneira, consoante um oráculo que tinha sido dado pelo adivinho Calcas, de agradar Ártemis e, assim, receber os bons ventos necessários para a navegação até Troia. Pois bem, Agamêmnon arrepende-se desta ideia e envia uma segunda carta desfazendo a missão dada pela primeira. Esta missiva, contudo, nunca saiu de Áulis, pois Menelau a interceptou. Por conseguinte, Clitemnestra, cumprindo o que estava dito na primeira correspondência, chega a Áulis com a filha.

Quando Agamêmnon vê sua família no meio dos gregos, ele desalenta-se inteiramente, acreditando que está completamente arruinado, pois os aqueus irão obrigá-lo a sacrificar Ifigênia (versos 506-514). Esta reação é surpreendente, uma vez que, segundo o prólogo da peça, além de Agamêmnon e Calcas (o adivinho), apenas Odisseu e Menelau sabiam do oráculo e do plano das falsas bodas de Ifigênia e Aquiles. Sendo assim, como os soldados gregos poderiam forçar o pai de Ifigênia a realizar o sacrifício se eles não teriam tido contado com nenhum relato que exigisse a morte da jovem?

IA é marcada por uma profunda incoerência narrativa: o sacrifício de Ifigênia é apresentado como uma trama planejada por Agamêmnon e seu círculo íntimo, porém, em vários momentos da peça (por exemplo, versos 914; 1267-1272; 1346), as personagens têm como certo que o exército grego forçará Agamêmnon a realizar o sacrifício, quer ele queira ou não. Como argumentou o editor da Ifigênia em Áulis da coleção Loeb Classical Library, Kovacs (2002; 2003), este conflito entre uma versão privada do oráculo acerca do sacrifício de Ifigênia, restrita ao grupo íntimo de Agamêmnon, e uma versão pública, na qual todos no acampamento saberiam do desejo de Ártemis, é resultado, muito provavelmente, do trabalho de um (ou mais) autor posterior a Eurípides que manipulou o texto e adicionou o motivo do oráculo privado sem eliminar por completo a intriga original baseada no conhecimento público dos termos do sacrifício. Assim, IA é uma peça cuja autoria não é exclusivamente de Eurípides. Há diversos problemas linguísticos, métricos e textuais que indicam que parte de $I A$ não é sequer do século V a.C. O final da peça, por exemplo, é considerado interpolado por quase todos os especialistas.

As interpolações de autores posteriores a Eurípides são tão evidentes que o editor de Oxford de IA, Diggle (1994), elaborou um esquema com quatro graus de autenticidade e

1 Pós-doutorando em Letras Clássicas na Universidade de São Paulo (USP). Trabalho financiado pela Fundação de Amparo à Pesquisa do Estado de São Paulo (FAPESP). Projeto de pesquisa: "O tema da crise e salvação da cidade em Eurípides e Aristófanes". 
classificou cada verso da peça de acordo com um destes níveis de atribuição de autoria. Assim, há versos "possivelmente euripidianos" (fortasse Euripidei), "possivelmente não euripidianos" (fortasse non Euripidei) "dificilmente euripidianos" (uix Euripidei), "não euripidianos" (non Euripidei). Diggle classifica no nível mais elevado de autenticidade, "possivelmente euripidiano", aproximadamente 680 do total de 1629 versos, isto é, somente $41.7 \%$ do que lemos pode ter vindo realmente das mãos de Eurípides.

Desse modo, como nota Lourenço (2008), “a Ifigénia não pode ser julgada por meio do recurso a critérios convencionais: toda a discussão literária em torno desta peça terá de reconhecer à partida, e nunca perder de vista, a natureza díspar do material poético" (p. 87-8). Nesse sentido, IA é uma das tragédias mais difíceis de analisar em relação à autoria, à autenticidade do texto e ao desenvolvimento da ação trágica.

Por este motivo, IA de Collard e Morwood (2017) - daqui em diante, C\&M - ocupa um lugar único na série de tradução e comentários a textos gregos "Aris and Phillips Classical Texts". Desde a década de oitenta, quando iniciou esta coleção, nunca uma obra da literatura grega tinha merecido dois volumes e uma quantidade tão substancial de páginas. O primeiro volume contém o prefácio, a introdução, o texto grego e a tradução inglesa, ao passo que o segundo volume é dedicado ao comentário filológico e literário, bem como aos indexes. As páginas dos dois volumes são contínuas (o segundo iniciando na página 235), de maneira que as citações abaixo incluirão as páginas o que, por si só, indicará a qual dos dois volumes estamos nos referindo.

No prefácio, C\&M reconhecem o caráter bastante problemático do texto de $I A$ e lembram que o último comentário em inglês ao texto grego desta tragédia foi feito por England (1891). De fato, a edição comentada de C\&M preenche uma importante lacuna nos Estudos Clássicos ao oferecer um rico comentário ao texto grego da peça, trazendo uma dosagem equilibrada entre discussões textuais e literárias.

A longa introdução (62 páginas) cobre diferentes aspectos do estudo do texto de $I A$, tais como o mito do sacrifício de Ifigênia antes de Eurípides, a caracterização das personagens e do Coro, a estrutura métrica dos versos, as ressonâncias políticas da peça no momento de sua apresentação original, o estado da discussão acerca da autenticidade e das interpolações na peça, readaptações deste drama no teatro moderno, além de outros temas evocados em $I A$, como a ideia de sacrifício, de casamento, o panhelenismo, as bruscas mudanças de ideia das personagens, o sentido de honra, a fortuna, o jugo da necessidade e o desejo de glória.

C\&M declaram, na introdução, seu posicionamento diante do debate sobre a autenticidade e os problemas textuais de $I A$. Eles preferem adotar uma atitude relativamente conservadora em relação à tradição manuscrita, evitando considerar muitos versos como suspeitos de interpolação (p. 58). Eles acreditam que a origem e o espírito de $I A$ são euripidianos (p. 58). Assim, C\&M sustentam a autenticidade de determinados conjuntos de versos que foram marcados por Diggle como dificilmente euripidianos. Os principais são: o debate entre Agamêmnon e Menelau nos versos 404-412; o primeiro discurso de Aquiles na peça (801-818); a resposta de Aquiles à súplica de Clitemnestra que tenta salvar Ifigênia, incluindo o desdobramento imediato desta cena (919-1035); o diálogo entre Agamêmnon e Clitemnestra nos versos 1098-1119. Mesmo a intervenção do mensageiro nas linhas 413-439 é encarada como autêntica por C\&M, apesar de Diggle ter classificado estes versos como não euripidianos.

Edição do texto grego caminha de maneira inseparável, no caso de $I A$, com interpretação literária. Ao sustentar a autenticidade de um número bem maior de versos do que o 
editor de Oxford, Diggle (1994), ou o editor da Loeb, Kovacs (2002), C\&M minimizam, de certo modo, as incoerências na narrativa de que tratamos acima. São, naturalmente, escolhas justificáveis, mas o leitor que tiver lido com atenção a Kovacs (2003), que explora estas incoerências na narrativa em profundidade, não deixará de achar alguns argumentos de C\&M pouco persuasivos a este respeito. Por exemplo, a leitura de C\&M (p. 241-43) acerca da famosa contradição entre a afirmação de Agamêmnon nos versos 106-107 de que só ele, Calcas, Menelau e Odisseu sabiam do plano de enganar Ifigênia com um falso casamento e a observação do Servo nas linhas 124-126 de que, com o cancelamento do casamento advindo da segunda carta, Aquiles ficaria furioso por não ter mais as bodas. Ora, esta observação do Servo não faz sentido, pois Aquiles não teria como ficar irado com o cancelamento de um matrimônio que, pela apresentação da intriga feita em 106107, ele nunca teria ouvido falar! C\&M (p. 241-43) tentam salvar o texto de contradição ao recorrer a um excesso de psicologismo: o Servo estaria aqui prevendo que Aquiles poderia ficar irado se ele, Aquiles, soubesse que teria existido um plano inicial de usar o seu nome para oferecer um falso casamento a Ifigênia. Uma tal elaboração interior de pensamento, com suposições sobre reações hipotéticas e futuras de outras figuras dramáticas, por parte de uma personagem anônima, não condiz em nada com a tragédia grega, como já foi afirmado por Bain (1977).

Já os detalhes da argumentação de C\&M sobre as escolhas editoriais e de autoria do texto grego estão contidos no segundo volume, especialmente em duas rubricas criadas pelos autores para tratar estes assuntos no comentário, Greek e Text. A mera existência destas seções já evidencia que a discussão filológica direcionada aos problemas textuais e de autoria nesta obra excede qualquer outro volume da coleção Aris and Phillips.

Naturalmente, a complexidade desta matéria não tem como ser tratada nesta resenha. Registro e louvo, todavia, o esforço dos autores em simplificar esse assunto, bem como em trazer para o leitor as opiniões dos outros especialistas sempre de uma maneira clara, ponderada e respeitosa. A discussão de C\&M (p. 238-40) sobre a debatida autenticidade do prólogo desta peça ilustra meu ponto. Eles organizam, de maneira bem didática, as hipóteses dos especialistas sobre esta questão em nove categorias, nas quais o espectro de opiniões abrange desde aqueles que defendem a autenticidade de (quase) todo o prólogo com a sequência métrica anapesto-iâmbico-anapesto que está presente nos manuscritos até estudiosos que sustentam que, afinal, nós temos duas versões alternativas e concorrentes do prólogo, nenhuma das quais teria Eurípides como autor.

A seção de comentário do segundo volume é, assim, preciosa para o entendimento das questões filológicas e literárias que envolvem o estudo aprofundado de uma tragédia grega, requerendo um conhecimento mínimo de grego antigo por parte do leitor. Gostaria de terminar esta resenha trazendo à luz certos argumentos dos autores presentes no comentário que, a meu ver, são particularmente felizes por aperfeiçoar nosso entendimento da construção de $I A$ enquanto tragédia e obra literária.

C\&M (p. 268-70) não aceitam, com muita razão, a ideia de alguns estudiosos, por exemplo, Fialho (2016), de que o oráculo de Calcas anunciado no início da peça seria uma artimanha do adivinho para se aproveitar do desespero da armada confinada em Áulis, sendo uma espécie de oráculo enganoso introduzido por Eurípides para enfatizar a avidez dos gregos em favor da guerra. Contrariamente a esta leitura, é importante registrar, na linha seguida por C\&M, que a legitimidade divina do oráculo de Calcas é um pressuposto da peça e da tradição mítica, de modo que não há razão para que seja ignorada pela crítica. 
Em relação à caracterização das personagens e de suas recorrentes mudanças de ideia, C\&M (p. 369) posicionam-se, corretamente, contra os comentadores que encaram a mudança de ideia de Menelau (473-503) como um recurso dissimulado que finge ter empatia pela sorte de Ifigênia e pelo dilema de Agamêmnon de ter que sacrificar a filha. Em tempos nos quais a crítica recorre muito facilmente a leituras irônicas das personagens trágicas, isto é, como se elas deliberadamente estivessem dizendo o oposto do que pensam, acredito que é oportuno reproduzir as palavras de C\&M quando explicitam um princípio de método ao se estudar as figuras da tragédia: "personagens dramáticas não devem ser encaradas como se seu significado fosse o oposto total ao que elas estão dizendo, a menos que exista evidência conclusiva de que elas estão fazendo isso" (p. 369).

Para concluir, uma palavra sobre o pertinente tratamento feito por C\&M do mito do sacrifício de Ifigênia antes de Eurípides. Ao se estudar uma tragédia grega, com efeito, é sempre produtivo averiguar o tratamento que o mito teve antes da peça em questão. Assim é possível identificar momentos chaves nos quais o tragediógrafo segue ou se afasta de determinadas maneiras mais estabelecidas de contar estas velhas histórias. Em IA, como notam C\&M (p. 4-6), os líderes gregos, a princípio, possuem a opção de navegar de volta para casa, o que contrasta com o que é narrado por Electra na peça homônima de Sófocles, na qual os gregos, aparentemente, estão presos em Áulis, impossibilitados seja de ir à Troia, seja de voltar para casa. A escolha de Eurípides residiu, portanto, em agudizar o drama de Agamêmnon, assim como o conflito entre os chefes e a armada grega, uma vez que o regresso aparecia como uma opção viável. Ainda em $I A$, o castigo de Ártemis de impossibilitar ventos favoráveis para a navegação até Troia aparece desmotivado, haja vista que, nesta peça, Agamêmnon está isento de qualquer tipo de impiedade diante da deusa. Uma vez mais, Eurípides altera a versão em relação a outros tratamentos do mito para conferir um significado específico à sua proposta dramática. Por último, o sacrifício voluntário de Ifigênia, que é a grande reviravolta na economia de uma peça ela própria caracterizada por mudanças bruscas de opinião das personagens é, para C\&M (p. 4), uma provável invenção de Eurípides, o que adiciona mais significado para o efeito que o tragediógrafo quis gerar na audiência, ainda que Eurípides já estivesse morto quando a peça, muito provavelmente em 405 a. C, foi encenada pela primeira vez.

Os volumes concluem com um index geral, um index das principais palavras gregas discutidas e uma seletiva lista de passagens discutidas da literatura grega.

Esta obra é certamente fundamental para quem deseja explorar os detalhes da construção literária de Ifigênia em Áulis. Faço votos que pesquisadores (as) possam ter acesso a este material e que as bibliotecas públicas possam adquirir este substancial estudo sobre Ifigênia em Áulis de Eurípides.

\section{Referências}

BAIN, D. The Prologues of Euripides' Iphigenia in Aulis. The Classical Quartely vol. 27.Cambridge: Cambridge University Press, p. 10-26, 1977.

COLLARD, C.; MORWOOD, J. Euripides. Iphigenia at Aulis. Vol 1. Liverpool:

Liverpool University Press, 234 páginas, 2017. . Euripides. Iphigenia at Aulis. Vol 2. Liverpool: Liverpool University Press, 421

páginas, 2017. 
DIGGLE, J. Euripides Fabulae vol 3. Oxford: Clarendon Press, 1994.

ENGLAND, E. B. The Iphigenia at Aulis. London: Macmillan, 1891.

FIALHO, M. C. Z. A febre da guerra: retórica e demagogia em Ifigénia em Áulide.

Revista Ágora. Estudos Clássicos em debate, vol. 18, p. 81-98, 2016.

KOVACS, D. Euripides, Bacchae, Iphigenia at Aulis, Rhesus. London: Harvard University Press, 2002.

. Toward a Reconstruction of Iphigenia Aulidensis. The Journal of

Hellenic Studies, vol. 123, p. 77-103, 2003.

LOURENÇO, F. M. B. Sobre o Prólogo de Ifigénia em Áulis. In: LOURENÇO, F. Novos Ensaios Helénicos e Alemães. Lisboa: Cotovia, 2008.

Recebido em: 05/06/2020; Aceito em: 16/06/2020 